\title{
The association between Lambert-Eaton myasthenic syndrome and small cell lung carcinoma
}

\author{
Sarah EW Briggs' \\ Paul Gozzard² \\ Denis C Talbot ${ }^{3}$ \\ 'Department of Oncology, \\ Oxford University Hospitals Trust, \\ Churchill Hospital, Oxford, UK; \\ ${ }^{2}$ Nuffield Department of Clinical \\ Neurosciences, University of Oxford, \\ John Radcliffe Hospital, Oxford UK; \\ ${ }^{3}$ Department of Oncology, Oxford \\ University Hospitals Trust, Churchill \\ Hospital, Oxford, UK
}

\author{
This article was published in the following Dove Press journal: \\ ImmunoTargets and Therapy \\ 21 May 2013 \\ Number of times this article has been viewed
}

Abstract: Lambert-Eaton myasthenic syndrome (LEMS) is an autoimmune disorder mediated by autoantibodies to voltage-gated calcium channels. The disorder is diagnosed clinically on the basis of a triad of symptoms (proximal muscle weakness, hyporeflexia, and autonomic disturbance), supported by electrophysiological findings and the presence of autoantibodies. Between $40 \%$ and $62 \%$ of patients diagnosed with LEMS are found to have small-cell lung cancer (SCLC), almost all of whom develop neurological symptoms before their cancer is diagnosed. Prompt identification of LEMS and appropriate screening for SCLC is key to improving the outcome of both conditions. Here we review the pathophysiology and clinical management of LEMS, focusing particularly on the relationship with SCLC.

Keywords: Lambert-Eaton, small-cell lung cancer, autoimmune

\section{Definition and historical perspective}

The Lambert-Eaton myasthenic syndrome (LEMS) is an autoimmune disease characterized by weakness, reduced reflexes, and autonomic involvement ${ }^{1}$ thought to be mediated by antibodies to voltage-gated calcium channels (VGCCs) at the neuromuscular junction.

\section{Historical context}

A condition similar to myasthenia gravis related to bronchial neoplasms was first reported as a clinical entity in 1953. Anderson et al described the case of a 47-year-old whose muscle weakness had improved with excision of a small-cell lung cancer (SCLC). ${ }^{2}$ In 1954, Heathfield and Williams described a patient presenting with progressive proximal muscle weakness responsive to neostigmine, thought to be atypical myasthenia gravis, 18 months before developing lung cancer. ${ }^{3}$ In 1956 Lambert et al of the Mayo Clinic published a case series of six myasthenic-like patients with suspected or confirmed lung cancer and demonstrated the presence of neuromuscular conduction defects resulting in proximal muscle weakness. ${ }^{4}$

\section{Pathophysiology of LEMS}

Eaton and Lambert used electromyography (EMG) to show that a reduced amplitude of initial action potential on single maximal stimulation was followed by marked fatigability as seen in myasthenia but, in contrast to myasthenia gravis, facilitation of the action potential at higher rates of stimulation persisted for several seconds following voluntary exercise. ${ }^{5}$ In 1957 Eaton and Lambert published their seminal paper on the use of EMG in neuromuscular disorders, identifying six LEMS patients
Correspondence: Denis Talbot Department of Oncology,

Oxford University Hospitals Trust,

Churchill Hospital, Oxford,

OX3 7DQ, UK

Tel +44 I8 65235315

Email denis.talbot@oncology.ox.ac.uk
(C) 2013 Briggs et al, publisher and licensee Dove Medical Press Ltd. This is an Open Access article which permits unrestricted noncommercial use, provided the original work is properly cited. 
using this technique and noting the importance of EMG in differentiation from classical myasthenia gravis. ${ }^{5}$ They also defined the clinical characteristics of this group, with proximal muscle weakness, fatigability, reduced deep tendon reflexes, and temporary improvement in strength after brief exercise. Response to drugs was also noted to be different in patients with LEMS to that seen in myasthenia gravis, with poorer neostigmine response and heightened sensitivity to curare.

The role of acetylcholine in the pathology of the syndrome was further elucidated in the 1970s. Lambert and Elmqvist used in vitro studies of intercostal muscles from twelve patients with the syndrome. They showed reduction in the number of acetylcholine quanta released from the motor end plate in a calcium dependent fashion, suggesting long-term presynaptic disruption in LEMS. Quantal release increased with repetitive nerve stimulation, in line with EMG findings. ${ }^{6}$

\section{Immunological basis of disease}

The immunological basis of the disorder was first established by Lang et $a 1,{ }^{7}$ and Newsom-Davis et a ${ }^{8}$ who clearly demonstrated that LEMS is an antibody mediated condition in clinical and laboratory studies. In patients with both carcinomatous and non-carcinomatous LEMS, symptoms improved following plasma exchange resulting in improvements in EMG criteria in several patients. Similarly, immunosuppressive treatment with prednisolone and azathioprine resulted in clinical and electrophysiological improvement. Passive transfer experiments were then performed in mice, in which immunoglobulin (IgG) from the patients' serum was injected intraperitoneally. This treatment resulted in reduction in the compound muscle action potential, and quantal component of the end plate potential, but no alteration in the density of acetylcholine receptors.

Lindstrom and Lambert reported that, in contrast to myasthenia gravis, autoantibodies to the acetylcholine receptor were not present in sera of patients with LEMS. ${ }^{9}$ The presynaptic target of the autoantibodies, suggested by the reduced quantal release of acetylcholine, was supported by freeze fracture electron microscopy of neuromuscular junctions of patients with LEMS, which showed reduced numbers of active zones. ${ }^{10}$ Similarly, passive transfer of LEMS IgG to mice resulted in depletion of the active zones, which are considered to be the morphological representation of voltage-gated calcium channels (VGCC). ${ }^{11}$ An interaction with VGCC was also suggested by evidence that IgG from patients with LEMS had the same effect on membrane currents as magnesium ions, ${ }^{12}$ and was subsequently shown to reduce potassium-induced calcium flux in SCLC lines in vitro. It was proposed that cross-reaction with similar channels on motor nerve terminals could lead to the clinical phenotype. ${ }^{13}$ Lang et al subsequently showed that $\operatorname{IgG}$ from patients with LEMS acted on presynaptic VGCC channels by downregulation. ${ }^{14}$ Further electron microscopy studies showed that divalent $\operatorname{IgG}$ was required for depletion of the active zones,,$^{15}$ and that the inhibition of calcium flux was time and dose dependent. ${ }^{16}$

\section{Clinical features Epidemiology}

Of patients diagnosed with LEMS the incidence of SCLC in studies ranges from around $40 \%$ to $62 \%{ }^{1,17-20}$ Tumor associated LEMS (T-LEMS) is almost entirely due to SCLC; other tumors have been reported in association with LEMS (for example non-small-cell lung cancer, ${ }^{1}$ prostate cancer, ${ }^{21}$ and thymoma ${ }^{22,23}$ ) but these are likely to represent incidental findings. The incidence of T-LEMS is greatest in men over $50 ;{ }^{24-26}$ in non-tumor LEMS (NT-LEMS) there are two peaks in incidence, at 35 and 60 years, with a female preponderance in the lower age group and broadly equal sex distribution in the older group. ${ }^{24} \mathrm{~A}$ link to the HLA-B8-DR3 haplotype, which predisposes to autoimmune disease, is seen in the younger NT-LEMS cohort. ${ }^{27}$

\section{Presenting symptoms and signs}

LEMS was clinically characterized by O'Neill et al as a triad of proximal muscle weakness, reduced or absent reflexes, and autonomic involvement. ${ }^{1}$ In their series of 50 patients with LEMS, leg weakness was the presenting complaint in $62 \%$ of patients, generalized weakness in $12 \%$, arm weakness in $2 \%$, muscle ache or stiffness (with or without weakness) in $18 \%$, and autonomic symptoms in $6 \%$ (which included dry mouth, impotence, constipation, blurred vision, and reduced sweating). Over the course of the illness, all patients developed lower limb weakness, 78\% upper limb weakness, $36 \%$ muscle aches and pains, and $80 \%$ autonomic symptoms. Muscle weakness was noted to be predominantly in a proximal distribution, and many patients noted fatigability. Three (6\%) patients developed respiratory muscle weakness requiring ventilation. The presenting symptoms in O'Neill's seminal paper are summarized in Table 1; the authors could not identify any clinical features distinguishing NT-LEMS from T-LEMS. The most frequent signs elicited on examination were muscle weakness (92\%), reduced or absent 
Table I Presenting symptoms of LEMS

Leg weakness

Muscle ache or weakness

$62 \%$

Generalized weakness

Autonomic symptoms

Arm weakness

reflexes ( $92 \%$, with $78 \%$ showing post-tetanic potentiation) and cranial nerve abnormalities in $62 \%$ of patients, most commonly ptosis.

More recent studies have added to the clinical characterization. Nakao et al, ${ }^{17}$ in a study of 110 Japanese patients with LEMS, found a similar incidence of lower and upper limb weakness and hyporeflexia to that reported by O'Neill but the incidence of autonomic dysfunction was lower at $37 \%$, and they also noted cerebellar signs in $9 \%$ of their patients, all of whom had SCLC. The natural history is of weakness that progresses proximally to distally in all types of LEMS, and moves cranially to caudally. ${ }^{18}$ There is considerable variation in reports of bulbar and ocular involvement, which may be due to variation in timing of assessment after presentation. ${ }^{28}$ While external ophthalmoplegia does occur in LEMS, ${ }^{17}$ isolated oculomotor weakness is far less common than in MG. ${ }^{28}$ Given that some patients show postexercise facilitation (estimates of frequency of this vary, from $43.7 \%{ }^{2}$ to $\left.78 \%\right)^{1}$ deep tendon reflexes should be tested, after a period of relaxation..$^{28}$

\section{Clinical differentiation of T-LEMS from NT-LEMS}

A meta-analysis suggested that the clinical course was more rapid in paraneoplastic LEMS. ${ }^{25}$ Wirtz and colleagues conducted a study of 38 Dutch patients with LEMS and compared symptoms between tumor $(\mathrm{n}=13)$ and nontumor $(n=25)$ patients. ${ }^{26}$ In this small, retrospective study, the development of certain LEMS symptoms (mainly arm weakness, dysarthria, and erectile dysfunction) occurred more rapidly in those with SCLC. A subsequent larger study of 100 patients corroborated these findings. ${ }^{18}$ Distal leg weakness occurred significantly more frequently in SCLC patients; cerebellar ataxia was present in only $2 \%$ of patients with NT-LEMS compared to $16 \%$ of patients with SCLCLEMS, though this did not reach statistical significance.

\section{Diagnostics}

Clinical awareness is paramount and may be insufficient, as suggested by one series in which $32 \%$ of LEMS patients did not receive the correct diagnosis until more than 5 years after the onset of symptoms. ${ }^{30}$ LEMS is a clinical diagnosis with confirmation based on EMG findings (as described by Lambert et al, in 1956). ${ }^{4}$ VGCC antibodies, when present, provide further evidence of the diagnosis. ${ }^{28}$

The electrophysiological characteristics of LEMS are elicited following repetitive nerve stimulation. The initial compound muscle action potential (CMAP) is reduced compared to normal and then undergoes a decrement of at least $10 \%$ at low stimulating frequencies of $2-5 \mathrm{~Hz} .{ }^{31}$ However, this degree of decrement is also seen in myasthenia gravis and high frequency or postexercise stimulation is therefore needed to discriminate between these diagnoses. These methods are comparable in terms of sensitivity (84\%-96\%) but because high frequency stimulation is painful, postexercise recordings, which have a specificity of $100 \%$ for LEMS, are preferred. ${ }^{28}$ The increment after exercise is short-lived (half-life of increment at room temperature 15 seconds) ${ }^{32}$ and therefore recording needs to occur as soon as possible after exertion. An increment in CMAP amplitude of $\geq 100 \%$ at a frequency of $50 \mathrm{~Hz}$ is definitively abnormal, ${ }^{28}$ although it has been suggested that reducing this to $\geq 60 \%$ would improve sensitivity to $97 \%$, with minimal effect on specificity. ${ }^{33}$ The diagnostic features of LEMS are summarized in Table 2.

\section{Autoantibodies}

Many different autoantibodies have been identified as having a role in LEMS. Antibodies to P/Q-type VGCCs (as measured by radioimmunoprecipitation of toxin labeled $\mathrm{P} / \mathrm{Q}$ channels in cerebellar extract) appear to be responsible in the majority of cases and are specific to LEMS. ${ }^{28}$ These antibodies were found in all 32 cases of T-LEMS and in 30 of 33 patients with NT-LEMS in one study. ${ }^{34}$ While $\mathrm{P} / \mathrm{Q}$-type VGCC antibodies are specific to LEMS they have also been seen in a minority (3\%) of patients with SCLC but

Table 2 Diagnosis of LEMS

\begin{tabular}{ll}
\hline Clinical triad & $\begin{array}{l}\text { Proximal muscle weakness } \\
\text { Reduced or absent reflexes } \\
\text { Autonomic involvement }\end{array}$ \\
Supported by & Reduced CMAP \\
& Decrement of I0\% at low \\
& stimulating frequency \\
& High frequency/post exercise \\
& increment \\
& VGCC \\
\hline
\end{tabular}

Note: aRequired.

Abbreviations: CMAP, compound muscle action potential; EMG, electromyography. 
without LEMS. ${ }^{35,36} \mathrm{P} / \mathrm{Q}$-type VGCCs are expressed in SCLC cells, ${ }^{37}$ in which the antigenic epitope is thought to be within the alpha-1 subunit. ${ }^{38-40}$ In individual patients, the titer of the antibodies has been found to correlate inversely with disease severity. However in the population as a whole the absolute antibody titer does not correlate with electrophysiological criteria of disease severity. ${ }^{41}$

Serum from a minority of LEMS patients has been found to bind to L- and N-type VGCCs (25\% and 30\%-40\% respectively), ${ }^{42,43}$ mostly in addition to $\mathrm{P} / \mathrm{Q}$-type antibodies, but anti-N-type antibody titers have been shown to evolve independently in a few patients. ${ }^{44}$ Characterization of the particular channel subtype targeted by the antibodies in LEMS has been established using human embryonic kidney cells, transfected with the genes encoding the different VGCC subtypes. Incubation of these transfected cell lines in IgG from six LEMS patients, with and without an associated tumor has demonstrated a significant reduction in number of P- and Q-type VGCC, with little effect on cell lines expressing the N-type, L-type or R-type channels. ${ }^{45}$

The P/Q VGCC is not only expressed by SCLC and at the neuromuscular junction, but also within the brain, with highest concentration being in the cerebellum. For this reason cerebellar tissue is used as a source of $\mathrm{P} / \mathrm{Q}$ VGCC for diagnostic tests, ${ }^{41}$ and may also account for the emergence of cerebellar symptoms in a minority of patients with LEMS. ${ }^{17,18,35,46}$ Why the cerebellar syndrome occurs in some patients but not others is not yet understood, but may relate to the integrity of the blood-brain barrier. ${ }^{28}$ Considerable plasticity has been demonstrated in neuromuscular VGCC expression levels in mice. It is postulated that this may explain the phenotypic variation in the severity of LEMS and effects of the antibody in different tissues. ${ }^{28}$ Using whole cell patch clamp techniques on cultured rat cerebellar and granule cell neurons, IgG purified from the serum from LEMS patients causes a significant reduction in the calcium currents through P-type VGCC, with no effect on N- or L-type VGCC. However, there is an increase in the proportion of the current carried by the R-type VGCC, possibly indicating a concomitant up-regulation in these channels. ${ }^{45}$

Other antibodies detected in LEMS include voltage-gated potassium channel, AMPAR, IA2, GABAB, GAD65, and synaptotagmin. ${ }^{47}$ While high titers of anti-VGCC antibodies have been seen in both T-LEMS and NT-LEMS, ${ }^{18} \mathrm{SOX}$ antibody, which binds to one of a family of DNA-binding transcription factors, is seen in approximately $65 \%$ of patients with T-LEMS and $0 \%-6 \%$ of NT-LEMS. ${ }^{24,48}$ There is little evidence to suggest that the accompanying antibodies have a role in the pathogenesis of the disease. ${ }^{28}$ The presence/ absence of SOX antibody has no useful impact on LEMS cancer prediction scores based on clinical criteria alone. ${ }^{24}$

The sensitivity of the P/Q VGCC LEMS assay in our center is $>90 \%$. Nevertheless, some patients (mostly nonparaneoplastic) with clinically proven LEMS are seronegative for $\mathrm{P} / \mathrm{Q}$ antibodies. Passive transfer experiments with $\mathrm{P} / \mathrm{Q}$ seronegative LEMS patients reduces the quantal release of the end plate potential, suggesting that a similar antibody mediated mechanism to typical P/Q VGCC positive LEMS. It may be that the antibodies produced by these patients do not bind the epitopes used in the detection assay, or are present at levels below the detection threshold antibodies or that the antibodies are against a different protein altogether. ${ }^{17,28}$

\section{Relationship with SCLC Natural history}

It is hypothesized that the neurological dysfunction in SCLC LEMS is triggered by the development of autoantibodies to the P/Q VGCC ectopically expressed in lung by the tumor, which cross-react with channels at the neuromuscular junction. The causal relationship is supported by remission of LEMS in the few patients with complete regression of their tumors following treatment. ${ }^{1}$

The majority of patients have neurological symptoms before the diagnosis of malignancy is made. For example in O'Neill's case series only one of 24 patients had a diagnosis of SCLC preceding the development of LEMS. ${ }^{1}$ While around $60 \%$ of LEMS patients are found to have SCLC, the incidence of LEMS in patients with SCLC is just $2 \%-3 \%{ }^{35,49}$ In the prospective study by Payne et al of the incidence of clinical and subclinical LEMS in 63 patients, five patients all with extensive stage SCLC ( $8 \%$ ) had elevated VGCC levels, although only two patients had clinical LEMS. ${ }^{35}$

It is not established whether the presence of LEMS is correlated with improved prognosis of SCLC. In a cohort of 15 LEMS SCLC patients, matched for sex, age at diagnosis, extent of tumor, and treatment with nonLEMS SCLC patients, survival was significantly longer in LEMS (17.3 months versus 10 months, $P=0.048) .{ }^{50}$ Whether this finding was due to immunogenic effects, or lead time bias due to earlier cancer diagnosis and treatment in patients presenting with LEMS, was uncertain. In a cohort of 100 SCLC patients enrolled consecutively in an on-going study of paraneoplastic disoders, SCLC patients with VGCC antibodies (with or without LEMS) did not have a significantly improved survival compared to those without antibodies (10.5 months compared to 8.9 months), 
while those with LEMS had a significantly longer survival of 19.6 months $(P=0.038) .{ }^{36}$ If on completion of the study it is found that all patients with antibodies but no neurological symptoms have prolonged survival, this may be due to immunoreactivity altering tumor behavior, as lead-time bias is avoided. If survival is prolonged only in those with the clinical syndrome it may be that the pathologically-active autoantibodies may yield a survival advantage suggested by Pellkofer et al, ${ }^{51}$ or that lead time bias is responsible for the survival difference. However, two other studies of SCLC found no correlation between the presence of VGCC antibodies and prognosis. ${ }^{35,52}$ Furthermore, Maddison and Lang $^{36}$ noted that of the four LEMS patients in their cohort of 100 , two had extensive stage disease at diagnosis, which was a similar rate to the whole cohort, suggesting that disease may not necessarily have been detected at an earlier stage.

Titulaer and colleagues extended their observations in the Dutch cohort of LEMS patients to develop a prediction score for the presence of SCLC in patients with LEMS, which was validated in a separate UK cohort. ${ }^{24}$ This DutchEnglish LEMS Tumor Association Prediction (DELTA-P) score allocates 1 point to each of the following present at diagnosis or within the following 3 months: age at onset of symptoms $\geq 50$ years, weight loss of more than $5 \%$, smoking at the time of diagnosis, bulbar involvement, presence of erectile dysfunction, and Karnofsky performance status less than 70 . Scores of $0-1$ gave a $0 \%$ and $2.6 \%$ chance of SCLC respectively, while scores of 5 and 6 gave a $96.6 \%$ and $100 \%$ chance of SCLC diagnosis over 3 years of follow-up (see Table 3). Differences in HLA-B8-DR3 and erythrocyte sedimentation rate, while significant in univariate analysis, had no discriminatory use in multivariate analysis and so were excluded from the DELTA-P score. The authors suggest that scores of 3 or more should prompt thorough screening of patients for SCLC.

Table 3 Components of the DELTA-P score

\begin{tabular}{ll}
\hline DELTA-P score & Score \\
\hline Bulbar involvement eg, Dysarthria & $\mathrm{I}$ \\
Erectile dysfunction in men & $\mathrm{I}$ \\
Loss of weight $>5 \%$ & $\mathrm{I}$ \\
Tobacco use at onset & $\mathrm{I}$ \\
Age at onset of symptoms $\geq 50$ years & $\mathrm{I}$ \\
Karnofsky Performance status $<70$ & $\mathrm{I}$ \\
\hline
\end{tabular}

Notes: A total score of 0 or I corresponds to a $0 \%$ to $2.6 \%$ chance of SCLC and virtually excludes the condition, a score of 4, 5, 6 corresponds to chances of SCLC of $93.5 \%, 96.6 \%$, and $100 \%$, respectively and is highly predictive. The probability of SCLC with a score of 3 is around 24\%. Reprinted with permission. (C) 20I I American Society of Clinical Oncology. all rights reserved. Titulaer MJ, Maddison P, Sont JK, et al. J Clin Oncol. 201 I;29(7):902-908.

Abbreviation: SCLC, small-cell lung cancer.
Patients with a new diagnosis of LEMS should be screened with CT chest and fluoro-deoxyglucose (FDG)-positron emission tomography (FDG-PET) if CT negative. The frequency of subsequent screening may then be moderated by their DELTA-P score. With a score of $0-1$ patients should be screened again after 6 months (subsequent screening being FDG-PET or CT), and if negative screening may cease; a score of 2 should prompt screening every 6 months for 2 years. With a score of 3 or more, the patients should be screened again after 3 months and subsequently every 6 months for 2 years and clinical evidence of SCLC sought. Thus clinical features of LEMS may be used to identify highrisk patients and establish a rational screening strategy that limits unnecessary imaging in those at low risk. ${ }^{24}$

\section{Management}

Treatment of LEMS initially involves symptomatic management. In cases of SCLC-LEMS treatment of the tumor is key, as this may result in remission of LEMS. Immunological therapy may be required in more severe cases.

Symptomatic management is mediated by drugs that increase acetylcholine release. Acetylcholinesterase inhibitors were used historically but the drug of choice is now 3,4-diaminopyridine (3,4DAP, amifampridine), which prolongs the action potential of motor neurons by blocking VGCCs. ${ }^{53}$ More recent evidence implicates an additional direct action on VGCCs. ${ }^{54}$ Pyridostigmine and guanidine may also be used for symptomatic management when 3,4DAP is not available. ${ }^{28}$

A Cochrane meta-analysis identified four randomized trials comparing 3,4DAP with placebo involving a total of 54 patients assessed for Quantitative Myasthenia Gravis (QMG) muscle score and EMG between 3 and 8 days of therapy ${ }^{55}$ In these studies, the QMG muscle score improved by a mean of 2.44 points ( $95 \%$ confidence interval 3.6 to 1.22 ) and CMAP amplitude improved by $1.36 \mathrm{mV}$ (95\% confidence interval 0.99 to 1.72 ) following 3,4DAP therapy. There were significant side effects associated with 3,4DAP including seizures, paresthesia, fatigue, and epigastric discomfort. Most side effects appear to be dose dependent thus limiting effectiveness.

Immunotherapy is used in LEMS when symptomatic control is ineffective. Prednisolone plus steroid sparing agents, typically azathioprine, are the mainstay of treatment. Immunosuppression was required in $70 \%$ of patients with NT-LEMS ${ }^{56}$ and $40 \%$ of patients with SCLC-LEMS. ${ }^{28}$ Intravenous immunoglobulin therapy is recommended as a third line option in patients with resistant muscle weakness ${ }^{57}$ 
based on evidence (graded moderate to high quality in the Cochrane review) from a placebo controlled crossover study of 11 patients that showed a small benefit. ${ }^{58}$ Plasma exchange may also provide short-term relief. ${ }^{20}$ Rituximab treatment has been reported in two UK LEMS cases; good clinical improvement was observed in both but Rituximab did not induce remission in either patient. ${ }^{59}$

\section{Conclusion}

LEMS is the most common paraneoplastic disorder associated with SCLC having a prevalence of approximately 3\%. Among LEMS patients, 40\%-62\% have cancer, which is almost always SCLC. The clinical syndrome includes a variety of debilitating symptoms related to motor and autonomic function, and confirmation of the diagnosis by EMG and serological tests is straightforward. Early diagnosis of LEMS is important because intervention improves clinical outcome and quality of life. There is still considerable work to be done to further understand the relationship between LEMS and malignancy. The mechanism of action of VGCC antibodies is well understood, but the disease process in seronegative patients needs clarification. Further investigation will have wider implications for our understanding of other autoimmune conditions. Studies of whether, and why, the presence of LEMS and autoantibodies affects prognosis of SCLC will not only clarify the pathology of LEMS but may also be relevant to other paraneoplastic syndromes. Although LEMS is relatively rare, early recognition of the neurological syndrome, and immediate screening for the underlying tumor, may enable prompt treatment of a particularly aggressive form of cancer.

\section{Acknowledgments}

We thank Dr Bethan Lang for her help in reviewing the manuscript. SEWB is in receipt of a Research Bursary from Cancer Research UK.

\section{Disclosure}

The authors have no conflicts of interest to declare in this work.

\section{References}

1. O'Neill JH, Murray NMF, Newsom-Davis J. The Lambert-Eaton myasthenic syndrome - a review of 50 cases. Brain. 1988;111(Pt 3): 577-596.

2. Anderson HJ, Churchill-Davidson HC, Richardson AT. Bronchial neoplasm with myasthenia; prolonged apnoea after administration of succinylcholine. Lancet. 1953;265(6799):1291-1293.

3. Heathfield KW, Williams JR. Peripheral neuropathy and myopathy associated with bronchogenic carcinoma. Brain. 1954;77(1):122-137.
4. Lambert EH, Eaton LM, Rooke ED. Defect of neuromuscular conduction associated with malignant neoplasms. Am J Physiol. 1956; 187(3):612-613.

5. Eaton LM, Lambert EH. Electromyography and electric stimulation of nerves in diseases of motor unit; observations on myasthenic syndrome associated with malignant tumors. JAMA. 1957;163(13):1117-1124.

6. Lambert EH, Elmqvist D. Quantal components of end-plate potentials in myasthenic syndrome. Ann NY Acad Sci. 1971;183(Nsep):183-199.

7. Lang B, Newsom-Davis J, Wray D, Vincent A, Murray N. Autoimmune aetiology for myasthenic (Eaton-Lambert) syndrome. Lancet. 1981;2(8240):224-226.

8. Newsom-Davis J, Murray N, Wray D, et al. Lambert-Eaton Myasthenic Syndrome - electro-physiological evidence for a humoral factor. Muscle Nerve. 1982;5:(9S):S17-S20.

9. Lindstrom JM, Lambert EH. Content of acetylcholine-receptor and antibodies bound to receptor in myasthenia-gravis, experimental auto-immune myasthenia-gravis, and Eaton-Lambert Syndrome. Neurology. 1978;28(2):130-138.

10. Fukunaga $H$, Engel AG, Osame M, Lambert EH. Paucity and disorganization of pre-synaptic membrane active zones in the LambertEaton myasthenic syndrome. Muscle Nerve. 1982;5(9):686-697.

11. Fukunaga H, Engel AG, Lang B, Newsom-Davis J, Vincent A. Passive transfer of Lambert-Eaton myasthenic syndrome with IgG from man to mouse depletes the presynaptic membrane active zones. Proc Natl Acad Sci U SA. 1983;80(24):7636-7640.

12. Lang B, Newsom-Davis J, Prior C, Wray D. The effect of passively transferred Lambert-Eaton myasthenic syndrome antibodies on the calcium sensitivity of transmitter release in the mouse. $J$ Physiol. 1984;357:P28-P28.

13. Roberts A, Perera S, Lang B, Vincent A, Newsom-Davis J. Para-neoplastic myasthenic syndrome IgG inhibits $\mathrm{Ca}-45(2+)$ flux in a human small cell-carcinoma line. Nature. 1985;317(6039):737-739.

14. Lang B, Newsom-Davis J, Peers C, Prior C, Wray DW. The effect of myasthenic syndrome antibody on presynaptic calcium channels in the mouse. J Physiol. 1987;390:257-270.

15. Nagel A, Engel AG, Lang B, Newsom-Davis J, Fukuoka T. LambertEaton myasthenic syndrome IgG depletes presynaptic membrane active zone particles by antigenic modulation. Ann Neurol. 1988; 24(4):552-558.

16. Lang B, Vincent A, Murray NMF, Newsom-Davis J. Lambert-Eaton myasthenic syndrome - immunoglobulin-G inhibition of $\mathrm{Ca}-2+$ flux in tumor-cells correlates with disease severity. Ann Neurol. 1989; 25(3):265-271.

17. Nakao YK, Motomura M, Fukudome T, et al. Seronegative LambertEaton myasthenic syndrome. Neurology. 2002;59(11):1773-1775.

18. Titulaer MJ, Wirtz PW, Kuks JBM, et al. The Lambert-Eaton myasthenic syndrome 1988-2008: A clinical picture in 97 patients. J Neuroimmunol. 2008;201:153-158.

19. Wirtz PW, van Dijk JG, van Doorn PA, et al. The epidemiology of the Lambert-Eaton myasthenic syndrome in The Netherlands. Neurology. 2004;63(2):397-398.

20. Tim RW, Massey JM, Sanders DB. Lambert-Eaton myasthenic syndrome: electrodiagnostic finding and response to treatment. Neurology. 2000;54(11):2176-2178.

21. Titulaer MJ, Verschuuren JJ. Lambert-Eaton myasthenic syndrome: tumor versus nontumor forms. Ann NY Acad Sci. 2008;1132:129-134.

22. Morimoto M, Osaki T, Nagara Y, Kodate M, Motomura M, Murai H. Thymoma with Lambert-Eaton myasthenic syndrome. Ann Thorac Surg. 2010;89(6):2001-2003.

23. Fernandez-Torron R, Arcocha J, Lopez-Picazo JM, et al. Isolated dysphagia due to paraneoplastic myasthenic syndrome with anti-P/Qtype voltage-gated calcium-channel and anti-acetylcholine receptor antibodies. Neuromuscul Disord. 2011;21(2):126-128.

24. Titulaer MJ, Maddison P, Sont JK, et al. Clinical Dutch-English Lambert-Eaton Myasthenic syndrome (LEMS) tumor association prediction score accurately predicts small-cell lung cancer in the LEMS. J Clin Oncol. 2011;29(7):902-908. 
25. Wirtz PW, Smallegange TM, Wintzen AR, Verschuuren JJ. Differences in clinical features between the Lambert-Eaton myasthenic syndrome with and without cancer: an analysis of 227 published cases. Clin Neurol Neurosurg. 2002;104(4):359-363.

26. Wirtz PW, Wintzen AR, Verschuuren JJ. Lambert-Eaton myasthenic syndrome has a more progressive course in patients with lung cancer. Muscle Nerve. 2005;32(2):226-229.

27. Wirtz PW, Willcox N, van der SlikAR, et al. HLA and smoking in prediction and prognosis of small cell lung cancer in autoimmune Lambert-Eaton myasthenic syndrome. J Neuroimmunol. 2005;159(1-2):230-237.

28. Titulaer MJ, Lang B, Verschuuren JJ. Lambert-Eaton myasthenic syndrome: from clinical characteristics to therapeutic strategies. Lancet Neurology. 2011;10(12):1098-1107.

29. Odabasi Z, Demirci A, Kim DS, et al. Postexercise facilitation of reflexes is not common in Lambert-Eaton myasthenic syndrome. Neurology. 2002;59(7):1085-1087.

30. Pellkofer HL, Armbruster L, Linke R, Schumm F, Voltz R. Managing non-paraneoplastic Lambert-Eaton myasthenic syndrome: clinical characteristics in 25 German patients. J Neuroimmunol. 2009; 217(1-2):90-94.

31. Medicine AQACAAoE. Practice parameter for repetitive nerve stimulation and single fiber EMG evaluation of adults with suspected myasthenia gravis or Lambert-Eaton myasthenic syndrome: summary statement. Muscle Nerve. 2001;24(9):1236-1238.

32. Maddison P, Newsom-Davis J, Mills KR. Decay of postexercise augmentation in the Lambert-Eaton myasthenic syndrome: effect of cooling. Neurology. 1998;50(4):1083-1087.

33. Oh SJ, Kurokawa K, Claussen GC, Ryan HF. Electrophysiological diagnostic criteria of Lambert-Eaton myasthenic syndrome. Muscle Nerve. 2005;32(4):515-520.

34. Lennon VA, Kryzer TJ, Griesmann GE, et al. Calcium-channel antibodies in the Lambert-Eaton syndrome and other paraneoplastic syndromes. N Engl J Med. 1995;332(22):1467-1474.

35. Payne M, Bradbury P, Lang B, et al. Prospective study into the incidence of Lambert Eaton myasthenic syndrome in small cell lung cancer. J Thorac Oncol. 2010;5(1):34-38.

36. Maddison P, Lang B. Paraneoplastic neurological autoimmunity and survival in small-cell lung cancer. J Neuroimmunol. 2008;201:159-162.

37. Mccann FV, Pettengill OS, Cole JJ, Russell JAG, Sorenson GD. Calcium spike electrogenesis and other electrical-activity in continuously cultured small cell-carcinoma of the lung. Science. 1981;212(4499):1155-1157.

38. Takamori M, Iwasa K, Komai K. Antibodies to synthetic peptides of the alpha 1A subunit of the voltage-gated calcium channel in LambertEaton myasthenic syndrome. Neurology. 1997;48(5):1261-1265.

39. Iwasa K, Takamori M, Komai K, Mori Y. Recombinant calcium channel is recognized by Lambert-Eaton myasthenic syndrome antibodies. Neurology. 2000;54(3):757-759.

40. Parsons KT, Kwok WW. Linear B-cell epitopes in Lambert-Eaton myasthenic syndrome defined by cell-free synthetic peptide binding. J Neuroimmunol. 2002;126(1-2):190-195.

41. Motomura M, Lang B, Johnston I, Palace J, Vincent A, Newsom-Davis J. Incidence of serum anti-P/Q-type and anti-N-type calcium channel autoantibodies in the Lambert-Eaton myasthenic syndrome. J Neurol Sci. 1997;147(1):35-42.

42. el Far O, Marqueze B, Leveque C, et al. Antigens associated with $\mathrm{N}$ - and L-type calcium channels in Lambert-Eaton myasthenic syndrome. J Neurochem. 1995;64(4):1696-1702.

ImmunoTargets and Therapy

\section{Publish your work in this journal}

ImmunoTargets and Therapy is an international, peer-reviewed open access journal focusing on the immunological basis of diseases, potential targets for immune based therapy and treatment protocols employed to improve patient management. Basic immunology and physiology of the immune system in health, and disease will be also covered. In addition, the journal will focus on the impact of manage-
43. Meriney SD, Hulsizer SC, Lennon VA, Grinnell AD. Lambert-Eaton myasthenic syndrome immunoglobulins react with multiple types of calcium channels in small-cell lung carcinoma. Ann Neurol. 1996; 40(5):739-749.

44. Martin-Moutot N, De Haro L, Seagar M. Distinct evolution of calcium channel antibody types in Lambert-Eaton myasthenic syndrome. J Neuroimmunol. 2008;197(1):47-53.

45. Pinto A, Gillard S, Moss F, et al. Human autoantibodies specific for the alpha(1A) calcium channel subunit reduce both P-type and Q-type calcium currents in cerebellar neurons. Proc Natl Acad Sci USA. 1998 ; 95(14):8328-8333.

46. Graus F, Lang B, Pozo-Rosich P, Saiz A, Casamitjana R, Vincent A. P/Q type calcium-channel antibodies in paraneoplastic cerebellar degeneration with lung cancer. Neurology. 2002;59(5):764-766.

47. Kazarian M, Laird-Offringa IA. Small-cell lung cancer-associated autoantibodies: potential applications to cancer diagnosis, early detection, and therapy. Mol Cancer. 2011;10:33.

48. Sabater L, Titulaer M, Saiz A, Verschuuren J, Gure AO, Graus F. SOX1 antibodies are markers of paraneoplastic Lambert-Eaton myasthenic syndrome. Neurology. 2008;70(12):924-928.

49. Wirtz PW, Lang B, Graus F, et al. P/Q-type calcium channel antibodies, Lambert-Eaton myasthenic syndrome and survival in small cell lung cancer. J Neuroimmunol. 2005;164(1-2):161-165.

50. Maddison P, Newsom-Davis J, Mills KR, Souhami RL. Favourable prognosis in Lambert-Eaton myasthenic syndrome and small-cell lung carcinoma. Lancet. 1999;353(9147):117-118.

51. Pellkofer HL, Armbruster L, Krumbholz M, et al. Lambert-Eaton myasthenic syndrome differential reactivity of tumor versus nontumor patients to subunits of the voltage-gated calcium channel. J Neuroimmunol. 2008;204(1-2):136-139.

52. Monstad SE, Drivsholm L, Storstein A, et al. Hu and voltage-gated calcium channel (VGCC) antibodies related to the prognosis of smallcell lung cancer. J Clin Oncol. 2004;22(5):795-800.

53. Molgo J, Lundh H, Thesleff S. Potency of 3,4-diaminopyridine and 4-aminopyridine on mammalian neuromuscular-transmission and the effect of pH changes. Eur J Pharmacol. 1980;61(1):25-34.

54. Wu ZZ, Li DP, Chen SR, Pan HL. Aminopyridines potentiate synaptic and neuromuscular transmission by targeting the voltage-activated calcium channel beta subunit. J Biol Chem. 2009;284(52):36453-36461.

55. Lindquist S, Stangel M. Update on treatment options for Lambert-Eaton myasthenic syndrome: focus on use of amifampridine. Neuropsych Dis Treat. 2011;7:341-349.

56. Maddison P, Lang B, Mills K, Newsom-Davis J. Long term outcome in Lambert-Eaton myasthenic syndrome without lung cancer. $J$ Neurol Neurosurg Psychiatry. 2001;70(2):212-217.

57. Patwa HS, Chaudhry V, Katzberg H, Rae-Grant AD, So YT. Evidencebased guideline: intravenous immunoglobulin in the treatment of neuromuscular disorders Report of the Therapeutics and Technology Assessment Subcommittee of the American Academy of Neurology. Neurology. 2012;78(13):1009-1015.

58. Bain PG, Motomura M, Newsom-Davis J, et al. Effects of intravenous immunoglobulin on muscle weakness and calcium-channel autoantibodies in the Lambert-Eaton myasthenic syndrome. Neurology. 1996;47(3):678-683.

59. Maddison P, McConville J, Farrugia ME, et al. The use of rituximab in myasthenia gravis and Lambert-Eaton myasthenic syndrome. J Neurol Neurosurg Psychiatry. 2011;82(6):671-673.

\section{Dovepress}

ment programs and new therapeutic agents and protocols on patient perspectives such as quality of life, adherence and satisfaction. The manuscript management system is completely online and includes a very quick and fair peer-review system, which is all easy to use. Visit http://www.dovepress.com/testimonials.php to read real quotes from published authors. 